\title{
Transport of the smoke plume from Chiado's fire in Lisbon (Portugal) sensed by atmospheric electric field measurements
}

Article

Accepted Version

Conceição, R., Melgão, M., Silva, H. G., Nicoll, K., Harrison, R. G. and Reis, A. H. (2016) Transport of the smoke plume from Chiado's fire in Lisbon (Portugal) sensed by atmospheric electric field measurements. Air Quality, Atmosphere \& Health, 9 (3). pp. 275-283. ISSN 1873-9318 doi:

https://doi.org/10.1007/s11869-015-0337-4 Available at https://centaur.reading.ac.uk/39871/

It is advisable to refer to the publisher's version if you intend to cite from the work. See Guidance on citing.

Published version at: http://dx.doi.org/10.1007/s11869-015-0337-4

To link to this article DOI: http://dx.doi.org/10.1007/s11869-015-0337-4

Publisher: Springer

All outputs in CentAUR are protected by Intellectual Property Rights law, including copyright law. Copyright and IPR is retained by the creators or other copyright holders. Terms and conditions for use of this material are defined in the End User Agreement. 


\section{www.reading.ac.uk/centaur}

\section{CentAUR}

Central Archive at the University of Reading

Reading's research outputs online 


\section{Transport of the smoke plume from Chiado's fire in Lisbon (Portugal) sensed by atmospheric electric field measurements}

Ricardo Conceição ${ }^{1}$, Marta Melgão ${ }^{1}$, Hugo G. Silva ${ }^{1,2, *}$, Keri Nicoll ${ }^{3}$, Richard G.

Harrison $^{3}$, António H. Reis ${ }^{1}$

${ }^{1}$ Departamento de Física, Instituto de Ciências da Terra (ICT), Universidade de Évora, Rua Romão Ramalho, 59, Évora, Portugal

${ }^{2}$ Atmospheric Chemistry Research Group, University of Bristol, Cantock's Close, Bristol, BS8 1TS, UK

${ }^{3}$ Department of Meteorology, University of Reading, Berkshire, RG6 6BB, UK

*Corresponding author:

Hugo G. Silva

Centro de Geofísica de Évora,

Universidade de Évora,

Rua Romão Ramalho, 59

Évora, Portugal

E-mail: hgsilva@uevora.pt 


\begin{abstract}
The Chiado's fire that affected the city centre of Lisbon (Portugal) occurred on $25^{\text {th }}$ August 1988 and had a significant human and environmental impact. This fire was considered the most significant hazard to have occurred in Lisbon city centre after the major earthquake of 1755. A clear signature of this fire is found in the atmospheric electric field data recorded at Portela meteorological station about $8 \mathrm{~km}$ NE from the site where the fire started at Chiado. Measurements were made using a Benndorf electrograph with a probe at $1 \mathrm{~m}$ height. The atmospheric electric field reached $510 \mathrm{~V} / \mathrm{m}$ when the wind direction was coming from SW to NE, favourable to the transport of the smoke plume from Chiado to Portela. Such observations agree with predictions using Hysplit air mass trajectory modelling and have been used to estimate the smoke concentration to be $\sim 0.4 \mathrm{mg} / \mathrm{m}^{3}$. It is demonstrated that atmospheric electric field measurements were therefore extremely sensitive to Chiado's fire. This result is of particular current interest in using networks of atmospheric electric field sensors to complement existing optical and meteorological observations for fire monitoring.
\end{abstract}

Keywords: Atmospheric Electric Field; Urban fire; Smoke and air pollution 


\section{Introduction}

Atmospheric electric field measurements have many applications in atmospheric sciences, e.g. (Matthews et al. 2010). In the literature it is usual to refer to Potential Gradient $^{1}(\mathrm{PG})$ defined as:

$P G=\frac{J_{z}}{\sigma_{t}}$

Here $J_{z}$ corresponds to the vertical air-Earth current density and $\sigma_{t}$ to the atmospheric electric conductivity (AEC). Where $\sigma_{t}$ is given by:

$\sigma_{t}=2 n \mu e$

where $n$ is the mean bipolar ion number concentration, $\mu$ is the mean ion mobility and $e$ the electronic charge. Furthermore, PG is defined to be positive in fair-weather days to Voeikov (1965), this means those days with cloudiness less than 0.3, wind speed less than $20 \mathrm{~km} / \mathrm{h}$ and absence either of fog or precipitation.

Among its different uses, sensing pollution with PG measurements is one of the most significant ones (Harrison 2006). Historical PG records have been used to infer pollution dynamics since the first reliable PG measurements were done in the midnineteenth (Aplin 2012 and references therein) to late twentieth century (Silva et al. 2014) when particulate matter measurements became abundant as part of routinely air quality control (Krzyzanowski and Cohen 2008). In this context, AEC was also proven to be very sensitive to air pollution (Retails et al. 1991; Sheftel et al. 1994). These studies show a decrease in AEC with the increase of air pollution; which does relate, through Eq. (1), to the increase of PG (Retalis and Retalis 1997; Silva et al. 2014). Actually, the reduction of the number of small ions caused by air pollution (Retails 1977 ) is the main mechanism behind these observations as it reduces considerably AEC. Details on the theory will be given below.

\footnotetext{
${ }^{1}$ The convention is that $P G=\mathrm{d} V_{I} / \mathrm{d} z$, where $V_{I}$ is the potential difference between the Ionosphere and Earth's surface and $z$ the vertical coordinate. It is defined to be positive for fair-weather days and is related with the vertical component of the atmospheric electric field by $E_{z}=-P G$.
} 
Due to its sensitive to air pollution a possible application of PG measurements is the detection of fires. These hazards represent an immense threat to public health and impose a strong environmental impact; which makes all possible tools available to their monitoring of fundamental importance. In the context of atmospheric electricity, initial interest in fires was related with lightning from fire-clouds (Vonnegut et al. 1995). It was found that the plumes of hot gas, moisture, and smoke formed by the fires originate anomalous lightning (Lang and Rutledge 2006) and disturb significantly the local PG (Phalagov et al. 2009). This perturbation is caused by the action of two distinct factors (Gopalakrishnet al. 1996): 1) the atmospheric ions created by the burning flame increasing AEC and decreasing PG; 2) the smoke spread with the plume scavenge the atmospheric ions decreasing AEC and increasing PG. The second factor dominates over the first (Ippolitov et al. 2013).

Presently, the use of PG measurements in sensing smoke plumes derived from fires is gaining vigour with the development of networks of PG sensors worldwide. In particular, in South America a PG network is operating (Tacza et al. 2014); this region comprises the Amazon rainforest (largest tropical rainforest in the world) and the use of this network could be of significant value in complementing visual and meteorological measurements.

In this perspective, the urban fire that occurred in Lisbon (Portugal) on $25^{\text {th }}$ August 1988, known as Chiado's fire, represents a rare opportunity (Figure 1) to study the effect of smoke particles on PG, as such measurements were made in the suburbs of Lisbon at Portela meteorological station (Serrano et al. 2006; Silva et al. 2014). Chiado's fire was considered the most significant hazard to have occurred in Lisbon city centre since the 1755 earthquake. It had a significant economical and human impact due to the destruction of many buildings, 2 people lost their lives, 73 were injured, and around 300 people lost their homes, while nearly 2000 lost their jobs. The fire started about 05:00 h (local time) at the Grandella store in Carmo Street (Chiado). Highly flammable and explosive materials were stored in the buildings affected by the fire, which contributed to its rapid spread and great magnitude. Firefighters fought this urban hazard until 16:00 h on $25^{\text {th }}$ August 1988 while smoke emissions last for several days (firefighters work in the zone went to $5^{\text {th }}$ September). In the end, Chiado's fire affected about $8000 \mathrm{~m}^{2}$, which corresponds to approximately $3.4 \%$ of Lisbon's downtown. 
Here it is discussed the impact that Chiado's fire had on the PG at Lisbon. The analysis of these records is complemented with air mass trajectory modelling, using Hysplit model (as no aerosol measurements or satellite monitoring was available during that period) and the examination of local meteorological conditions to evaluate the sensitivity of the PG to this urban fire.

\section{Results and Discussion}

The former Portuguese Meteorological Institute (IM) recorded PG at Portela meteorological station ( $38^{\circ} 46^{\prime} 12^{\prime \prime} \mathrm{N}, 9^{\circ} 07^{\prime} 41^{\prime \prime} \mathrm{W}$ ), located near Lisbon airport and NE from Chiado ( $38^{\circ} 42^{\prime} 43^{\prime \prime} \mathrm{N}, 9^{\circ} 08^{\prime} 22^{\prime \prime} \mathrm{W}$ ), since 1955 until 1990, using a Benndorf electrograph. The electrograph was coupled to a radioactive probe to secure equality of potential between the sensor and the air and also improving the time response of the electrograph (Shigeno et al. 2001). It was installed at $1 \mathrm{~m}$ above ground in a cement base recorded the PG at Portela meteorological station (Lisbon Airport, Portugal, as shown in Figure 1). Its sensitivity was checked using an electronic electrometer with standard voltage source between $\pm 200 \mathrm{~V}$ and the same calibration procedure was used in all periods of operation. The analogue records of the electrograph were digitalized afterwards (Serrano 2010). Further details on the dataset can be found in (Serrano et al. 2006; Silva et al. 2014). The hourly values of PG measured during 1988 are presented in Figure 2; the vertical green line marks the period in which Chiado's fire occurred, on $25^{\text {th }}$ August. Examination of Figure 2 shows that on the $26^{\text {th }}$ August the PG at Portela was significantly enhanced, reaching a maximum value of 510V/m at 19:00 h. Figures $3 \mathrm{a}$ and $3 \mathrm{~b}$ show the annual and summer PG histograms (in logarithmic scale) for 1988, respectively. This is because seasonal variations affect considerably the PG distribution. In Figure 3a,b it is seen that the PG distributions are not normal and are positively skewed (to the right), due to the predominantly positive PG values during fair-weather. Descriptive statistics for both distributions are presented in Table 1. The reliability of the $26^{\text {th }}$ August PG value as an outlier it is checked by the skewness of PG and by the statistics in Table 1. Additionally, taking into account that in the summer the mean PG is $75.4 \mathrm{~V} / \mathrm{m}$ and standard deviation is $46.1 \mathrm{~V} / \mathrm{m}$, this means that the PG anomaly was above the summer mean value more than 9 times its standard deviation. It was so large that such a value was only exceeded on two days in that year (recorded during foul- 
weather winter days). A stronger indicator is the estimation of the probability that such anomalous PG have to occur. To do so the distributions in Figure 3 are fitted to $t$ Location-Scale distributions (using maximum likelihood estimation) to calculate the probability of a value of $510 \mathrm{~V} / \mathrm{m}$ to occur. The results show that the probabilities are low: $\sim 0.13 \%$ in all the year and $\sim 0.08 \%$ in the summer.

Further analysis of the PG data can be achieved by considering its average diurnal variation; which is due to a combination of local and global effects. The black curve in Figure 4 shows the average diurnal variation in PG at Portela for 1988 having two maxima at approximately 08:00 $\mathrm{h}$ and 16:00 $\mathrm{h}$ (local time). This is consistent with daily particulate matter variations in urban environments (Harrison 2009). Plotted alongside is the PG data measured during the period of Chiado's fire: in red for $25^{\text {th }}$ and in blue for $26^{\text {th }}$ August. The large difference between the average diurnal PG variation and the one measured on $26^{\text {th }}$ August (which is much larger than the typical values) suggests the presence of an external factor driving the unusual PG changes. Therefore, such effect is attributed to the increase in smoke particle concentration generated by Chiado's fire. In fact, assuming that the smoke from Chiado's fire caused the large PG values over Portela, it is possible to estimate the concentration of smoke particles directly from the PG measurements through the theory developed by Harrison (2006). This is briefly derived from the ion balance equation:

$q-\alpha n^{2}-n \beta Z=0$

where $q$ is the ion production rate, $\alpha$ is the ion-ion recombination rate, $\beta$ is the ionaerosol attachment coefficient to monodisperse aerosols and $Z$ is the corresponding concentration number. In the case of heavy pollution, $n \beta Z \gg \alpha n^{2}$, Eq. (3) simply becomes:

$n=\frac{q}{\beta Z}$.

Substituting Eq. (4) in the equation for AEC, Eq. (2), and the result included in the formula for the PG, Eq. (1), it is found the relation: 
$P G=\frac{J_{z} \beta Z}{2 q \mu e}$

It is possible to substitute $Z$ in Eq. (5) by smoke mass concentration, $M$, through the relation, $Z=M / m$, with $m$ the mean mass of a single particle. Thus it is obtained the relationship:

$P G=\frac{J_{z} \beta}{2 q \mu e m} M$

This equation links the $P G$ directly to $M$. Finally, the measured $P G$ is written as the sum of two components: the one caused by the action of smoke particles, Eq. (6), and the one conforming to clean air, $P G_{0}$. This results in:

$P G=\frac{J_{z} \beta}{2 q \mu e m} M+P G_{0}$

Substituting the coefficient of $M$ in Eq. (7) by $C$ and isolating $M$, the smoke concentration can be retrieved as a function of $P G$ and $P G_{0}$ :

$M=C^{-1}\left(P G-P G_{0}\right)$.

The constant $C$ was estimated by Harrison (2006) for Kew (London) to be 1082.6 $(\mathrm{V} / \mathrm{m}) /\left(\mathrm{mg} / \mathrm{m}^{3}\right)$. Using Eq. (8) it is possible to make a reasonable estimation of $M$ at the PG maximum (510 V/m). The mean PG values for the Sundays of August 1988 is used as corresponding to clean air, $P G_{0} \sim 53 \mathrm{~V} / \mathrm{m}$. Sundays were chosen because they are the less polluted days of the week (Silva et al. 2014). The estimation indicates a maximum smoke concentration of $M \sim 0.4 \mathrm{mg} / \mathrm{m}^{3}$ at Portela ( $8 \mathrm{~km}$ from the origin of the fire) which is consistent with high smoke concentration scenario as expected for this fire. It is important to bear in mind that this is an indicative value. Moreover, it is expected that the value of $C$ for Lisbon might not differ significantly from London's, as both cases consider a high pollution scenario. Finally, using Eq. (8) a simple estimation for the threshold smoke concentration needed for a fire to be detected by PG measurements 
would be around $\sim 0.2 \mathrm{mg} / \mathrm{m}^{3}$; this assumes that a PG $\sim 300 \mathrm{~V} / \mathrm{m}$ is anomalous and $P G_{0}$ $\sim 53 \mathrm{~V} / \mathrm{m}$ (the one used above).

\subsection{Meteorological considerations}

PG is drastically affected by local weather conditions. It is therefore important to determine whether the anomalous PG values measured on $26^{\text {th }}$ August were in fact due to the increase in smoke concentration, caused by the fire, or resulted from local meteorological factors. Meteorological parameters at Portela meteorological station (the same location of PG records) were obtained from NNCD Climate Data Online website supported by NOAA. These include visibility, wind speed and direction, air temperature, and dew point (used to calculate relative humidity). Figure 5 shows the time series of the meteorological variables over Lisbon for the period $25^{\text {th }}$ and $26^{\text {th }}$ August 1988: (a) PG; (b) visibility; (c) wind speed; (d) wind direction; (e) relative humidity $(\mathrm{RH})$. These demonstrate that during the period of the fire there were fairweather conditions, according to Voeikov (1965). Some high cloud (above 5km) was present on $26^{\text {th }}$ and $27^{\text {th }}$, though. Such clouds, due to their high altitude (well above the boundary layer) cannot account for the large PG values measured at the time of the fire. The synoptic situation (not shown) during this period was characterized by a highpressure system over Portugal with mostly clear skies and no precipitation corresponding to quiet atmospheric conditions. Such conditions in summer are characterized by intense solar radiation that causes significant air convection. It is expected that the smoke plume due to its high temperature would have been injected well above the ground, but air convention would cause vertical dispersion of smoke particles. These would reach the ground during the travel time from Chiado to Portela. In fact, the increased smoke particle concentration from the fire could last for several days.

It can also be seen in Figures $5 \mathrm{~b}$ and $5 \mathrm{e}$ that visibility and $\mathrm{RH}$ have values that exclude the possibility of fog formation; this is important because fogs tend to increase the PG (Piper and Bennett 2012) and could be a possible cause for the anomalous PG discussed here. Besides, to account for the smoke plume transport from the fire's site to the PG measurement location, it is important to consider the wind direction on $25^{\text {th }}$ and $26^{\text {th }}$ 
August, Figure $5 \mathrm{~d}$. This shows that on the $25^{\text {th }}$ the wind was mainly coming from the north, $360^{\circ}$; whereas on the $26^{\text {th }}$ the wind direction started coming from east and then gradually from southwest, $240^{\circ}$. This process took $\sim 6$ hours to stabilize (the black arrow marks the stabilizing moment) and it is clearly seen in Figure 6 (withe arrow marks the wind rotation). After this it is observed that the PG starts to increase, up to its peak value $\sim 3$ hours later, Figure 5a. The smoke plume took roughly $\sim 1$ hour to travel from the fire's site to the measurement location. This is estimated dividing the distance from Chiado to Portela, $8 \mathrm{~km}$, by an average wind velocity of $\sim 2 \mathrm{~m} / \mathrm{s}$ (Figure $5 \mathrm{c}$ ). This means that there is a delay of $\sim 2$ hours between the plume arrival and the PG maximum. This delay is attributed to the time that smoke particles took to scavenge enough atmospheric ions to cause the significant decrease in AEC and consequently the anomalous increase in the PG. A simple estimation can be made taking into account that the lifetime of atmospheric ions in highly polluted air is 20 s (Retails 1991). Assuming that ion concentration before the fire was $\sim 500$ ions $/ \mathrm{cm}^{3}$ (Harrison and Carslaw 2003) an increase of the PG from a typical $\sim 100 \mathrm{~V} / \mathrm{m}$ to the anomalous $\sim 500 \mathrm{~V} / \mathrm{m}$ would imply, through Eq. (2), a reduction in atmospheric ions by $\sim 400$ ions $/ \mathrm{cm}^{3}$ (assuming that $J_{z}$ remained constant and the ion mobility did not change). Multiplying this value by the ion life time an estimation of the time needed for the process of ion scavenging to occur is calculate, $\sim 8000 \mathrm{~s}$, which corresponds to approximately 2 hours. Adding this estimation with the time for the smoke plume to travel gives $\sim 3$ hours, consistent with the observations. From the evolution of PG and visibility, Figures $5 \mathrm{a}$ and $5 \mathrm{~b}$, it can be seen that there was a reduction in the visibility, consistent with the transport of the plume to Portela station.

\subsection{Air mass trajectory modelling}

Air mass trajectories were calculated using the Hysplit- 4 model for air masses that started at the fire site at 05:00 $\mathrm{h}$ on the $25^{\text {th }}$ of August 1988 and ended at 20:00 $\mathrm{h}$ on the $26^{\text {th }}$. Despite the fact that the fire ended on 16:00 $\mathrm{h}$ of $25^{\text {th }}$ of August smoke emission remained during several days after (firefighters worked in the zone until $5^{\text {th }}$ September as mentioned above). In fact, meteorological conditions also favoured a late detection of the smoke plume by the PG in Portela. From Figure 7 it is possible to see the time evolution of the smoke particle trajectories between the fire site (marked with red pin) 
and the location where the PG was measured (pointed with a yellow pin). It is seen that the transport of the smoke plume evolves in a clockwise rotation from SW to the NE, and is estimated to pass over the PG measurement site at Portela between 17:00 $\mathrm{h}$ and 18:00 h (consistent with the minimum in visibility). Note also that this trajectory started at the source location at 16:00 h, which gives an approximately 1 hour to get to Portela, corroborating the estimation done before. The Hysplit trajectory shown in Figure 7 is also consistent with the change in wind direction shown in Figure 6, with the wind blowing from the fire site to the SW on $25^{\text {th }}$ and to the NE (in the Portela direction) on $26^{\text {th }}$ August. Additionally, using the Hysplit dispersion model, which for visualization effect can be more interesting, it was possible to simulate the smoke plume travelling path for $25^{\text {th }}$ and $26^{\text {th }}$ August (Figure 8). In Figure $8 \mathrm{a}$ at $17: 00 \mathrm{~h}$ on $25^{\text {th }}$, it is observed that the main concentration of the smoke plume is SW of Portela. By 07:00 h on $26^{\text {th }}$, Figure $8 \mathrm{~b}$, the smoke plume had spread W/NW, and by 18:30 h was over Portela region, Figure 8c. This effectively demonstrates that when the maximum in PG occurred, the main concentration of the smoke plume was above Portela. This approach was used to complement the trajectory model with improved visualization of the dispersion of the smoke particles by introducing information about the type of deposition (dry deposition), density $(1 \mathrm{~g} / \mathrm{cc})$ and particle diameter $(0.1 \mu \mathrm{m})$, and approximately 30 hours of emission (counting not only the fire duration but also the period when smoke was still being released). The density was chosen to be consistent with (Harrison 2006). Finally, the results support the argument that during the late afternoon of $26^{\text {th }}$ August a smoke plume from Chiado's fire passed over Portela causing the observed anomalously large PG values.

\section{Conclusions}

These results suggest that the Chiado's fire left a clear signature on the PG recorded at Portela. During the late afternoon of $26^{\text {th }}$ August 1988, one day after the fire, the PG increased to $510 \mathrm{~V} / \mathrm{m}$, which is an anomalously high value in comparison to the annual and summer distributions of PG at that site. This value is identified as an evident outlier with a reduced probability to occur, $\sim 0.08 \%$ in the 1988 summer. The analysis of wind speed and direction combined with calculations of forward trajectories using the Hysplit model enabled the assessment of the temporal and spatial evolution of the smoke plume. 
This analysis shows that the large PG values coincide with the approximate arrival time of the smoke plume at Portela. Finally, the analysis of the meteorological and synoptic conditions confirms that the anomaly of the PG does not result from meteorological effects. It is therefore likely that not only were the large PG values measured at Portela a result of the smoke plume from the Chiado's fire, but also, that measurements of PG can be used as a complementary method for fire detection, acting as a smoke proxy.

Future application of this finding may arise from networks of PG sensors, covering large areas, to complement other visual and meteorological variables with PG measurements in fire detection. It would enable the identification of the region where a fire is starting and the perception of the directions that the smoke plume is taking. Such information could be of determinant importance for fire hazard mitigation.

Funding: Portuguese Science and Technology Foundation (FCT) funded this research through the program Pest/OE/CTE/UI0078/2014. FCT also supported the participation of Hugo G. Silva (Postdoc grant: SFRH/BPD/63880/2009) and Marta Melgão (PhD

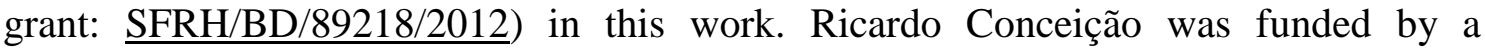
research grant from a FCT/COMPETE project FCOMP-01-0124-FEDER-029197 PTDC/GEO-FIQ/4178/2012, which Hugo G. Silva is responsible for.

Conflict of interests: The research here presented was not initially part of the research plan of FCOMP-01-0124-FEDER-029197 PTDC/GEO-FIQ/4178/2012 project.

\section{Acknowledgments}

The authors are grateful to the NOAA Air Resources Laboratory for the provision of the Hysplit transport and dispersion model and to Google Earth API for open the .kml file extension used in this article. Gratitude is expressed to Claudia Serrano and Samuel Bárias for digitalizing the data recorded Doctor Mário Figueira, who the authors also acknowledge. Hugo G. Silva acknowledges a discussion with José Fernando Borges that triggered the research here presented. Finally, special thanks are given to three anonymous reviewers for their valuable work in reviewing the initial manuscript. 


\section{References}

Aplin K (2012) Smoke emissions from industrial western Scotland in 1859 inferred from Lord Kelvin's atmospheric electricity measurements. Atmospheric Environment $50: 373-376$

Gopalakrishnan V, Deshpande, CG, and Kamra, A.K. (1996) Measurements of atmospheric electric field and conductivity in the locality of a gas well flame. Geophysical Research Letters 23(24):3615-3618

Harrison RG and Carslaw, KS (2003) Ion-aerosol-cloud processes in the lower atmosphere. Reviews of Geophysics 41(3):1012 (26pp)

Harrison RG (2006) Urban smoke concentrations at Kew, London, 1898-2004. Atmospheric Environment 40(18):3327-3332

Harrison RG (2009) Two daily smoke maxima in eighteenth century London air. Atmospheric Environment 43:1364-1366

Ippolitov II, Kabanov MV, Nagorskii PM, Pkhalagov YuA, and Smirnov SV (2013) Diurnal Variations in the Electrical Field Intensity under Smoke from Forest Fires. Doklady Earth Sciences 453(1):1137-1140

Krzyzanowski M, and Cohen A (2008) Update of WHO air quality guidelines. Air Quality Atmosphere and Health 1:7-13 
Matthews JC, Ward JP, Keitch PA, and Henshaw DL (2010) Corona ion induced atmospheric potential gradient perturbations near high voltage power lines. Atmospheric Environment 44:5093-5100

Lang TJ, and Rutledge SA (2006) Cloud-to-ground lightning downwind of the 2002 Hayman forest fire in Colorado. Geophysical Research Letters 33:L03804 (4pp)

Phalagov YuA, Ippolitov II, Nagorskii PM, Odintsov SL, Panchenko MV, Smirnov SV and Uzhegov VN (2009) Relation of Anomalous Atmospheric Conditions to Electric Field Variation. Atmospheric and Oceanic Optics 22(1):113-117

Piper IM, and Bennett AJ (2012) Observations of the atmospheric electric field during two case studies of boundary layer processes. Environment Research Letters 7:014017 (4pp)

Retalis DA (1977) On the relationship between small atmospheric ions concentration and (1) smoke, (2) sulfur dioxide and (3) wind speed. Pure and Applied Geophysics 115(3):575-581

Retalis D, Pitta A, and Psallidas P (1991) The conductivity of the air and other electrical parameters in relation to meteorological elements and air pollution in Athens. Meteorology and Atmospheric Physics 46(3-4):197-204

Retalis D, and Retalis A (1997) The atmospheric electric field in Athens - Greece. Meteorology and Atmospheric Physics 63(3-4):235-241 
Serrano C, Reis AH, Rosa R, and Lucio PS (2006) Influences of cosmic radiation, artificial radioactivity and aerosol concentration upon the fair-weather atmospheric electric field in Lisbon (1955-1991). Atmospheric Research 81:236-249

Serrano C (2010) Contribution to the study of atmospheric electric field in the Lisbon region. PhD Thesis, University of Évora, Portugal (in Portuguese)

Sheftel VM, Chernyshev AK, Chernysheva SP (1994) Air conductivity and atmospheric electric field as an indicator of anthropogenic atmospheric pollution. Jour Geophysical Research 99:10793-10795

Shigeno N, Takizawa T, Itoh N, Yokoyama M, and Owada T (2001) Preliminary Test for Atmospheric Electricity Measurement Using an Electrostatic Sensor. Translated to English from paper in Japanese, originally published in: Gijutsu Houkoku 41, 1(112):813

Silva HG, Conceição R, Melgão M, Nicoll K, Mendes PB, Tlemçani M, Reis AH, and Harrison RG (2014) Atmospheric electric field measurements in urban environment and the pollutant aerosol weekly dependence. Environment Research Letters 9:114025 (10pp)

Tacza J, Raulin J-P, Macotela E, Norabuena E, Fernandez G, Correia E, Rycroft MJ, and Harrison RG (2014) A new South American network to study the atmospheric electric field and its variations related to geophysical phenomena. Journal Atmospheric Solar-Terrestrial Physics 120:70-79

Vanderviere E, Huber M (2004) An Adjusted Boxplot for Skewed Distributions, COMPSTAT’2004 Symposium, Physuca-Verlag/Springer, 933-1940 
Voeikov AI (1965) Instruction on Preparation of the Material and Publication of the results of Atmospheric Electric Observations. Ed. Main Geophysical Observatory, Leningrad.

Vonnegut B, Latham DJ, Moore CB, and Hunyady SJ (1995) An explanation for anomalous lightning from forest fire clouds. Journal Geophysical Research 100:50375050 
Table 1 Mean, median, standard deviation, skewness, lower whisker, lower adjacent value, upper whisker and upper adjacent value for all year of 1988 (Annual) and Summer of 1988 (Summer). The last four statistical parameters were calculated trough adjusted boxplot method (Vanderviere and Huber, 2004).

\begin{tabular}{lcc}
\hline & Annual & Summer \\
Mean $(\mathrm{V} / \mathrm{m})$ & 88.9 & 75.4 \\
Median (V/m) & 80.0 & 70.0 \\
Standard deviation (V/m) & 58.2 & 46.1 \\
Skewness & 1.76 & 1.92 \\
Lower whisker (V/m) & 0.0 & -10.0 \\
Lower adjacent value (V/m) & 50.0 & 49.0 \\
Upper whisker (V/m) & 110.0 & 90.0 \\
Upper adjacent value (V/m) & 160.0 & 150.0 \\
\hline
\end{tabular}


Figure 1, Image of the Chiado's fire that took place at Lisbon city centre; courtesy of the Municipal Archive of Lisbon.

Figure 2, PG data measured at Portela during 1988 (the green line denotes the PG peak of Chiado's fire on $26^{\text {th }}$ August).

Figure 3, a) distribution of PG values for all the year of 1988; b) distribution of PG values for the summer of 1988. The arrows point to the anomalous PG value in study.

Figure 4, Hourly mean behaviour of the PG at Portela calculated from all year of 1988 (black curve), PG during $25^{\text {th }}$ (red curve) and $26^{\text {th }}$ of August 1988 (blue curve).

Figure 5, Meteorological conditions from $25^{\text {th }}$ and $26^{\text {th }}$ of August 1988 for Portela meteorological station (Lisbon airport): a) Potential Gradient; b) Visibility; c) Wind Speed; d) Wind Direction; e) Relative Humidity (RH). The vertical lines denote the start of the fire (first green line) and the PG peak hour (second green line). The horizontal red dash line in c) marks the fair-weather limit for wind speed, $6 \mathrm{~m} / \mathrm{s}$, according to Voeikov (1965). The black arrow in d) marks the moment when the smoke plume started travelling to Portela.

Figure 6, Rose wind representation in Portela during 1988 (a 3D perspective is used). The white arrow marks wind rotation in time from $25^{\text {th }}$ of August at 07:00 up to $26^{\text {th }}$ of August at 18:00 (UTC). These moments are marked in the figure. The wind speed varies according to 4 colours increasing its magnitude from light blue, dark blue, green and yellow. The increasing radius represents an increase in the observations. The Chiado's fire is marked with red pin and Portela station marked with a yellow one.

Figure 7, Forward trajectories calculated using Hysplit-4 for air masses at $750 \mathrm{~m}$ starting at 05:00 h $25^{\text {th }}$ August (first white trajectory) with a new trajectory created each 
5 hours (blue trajectories) until 16:00 h 26 ${ }^{\text {th }}$ August (last black trajectory). The Chiado's fire is marked with red pin and Portela station marked with a yellow one. NOAA Air Resources Laboratory.

Figure 8, Model projections of the plume spread from Chiado's fire: a) 25 ${ }^{\text {th }}$ August, 17:00 h; b) $26^{\text {th }}$ August, 07:00 h; c) $26^{\text {th }}$ August, $18: 30 \mathrm{~h}$; The smoke particle concentration varies according to 4 colours increasing its magnitude from light blue, to dark blue, green and yellow. The Chiado's fire is marked with red pin and Portela station marked with a yellow one. NOAA Air Resources Laboratory. 


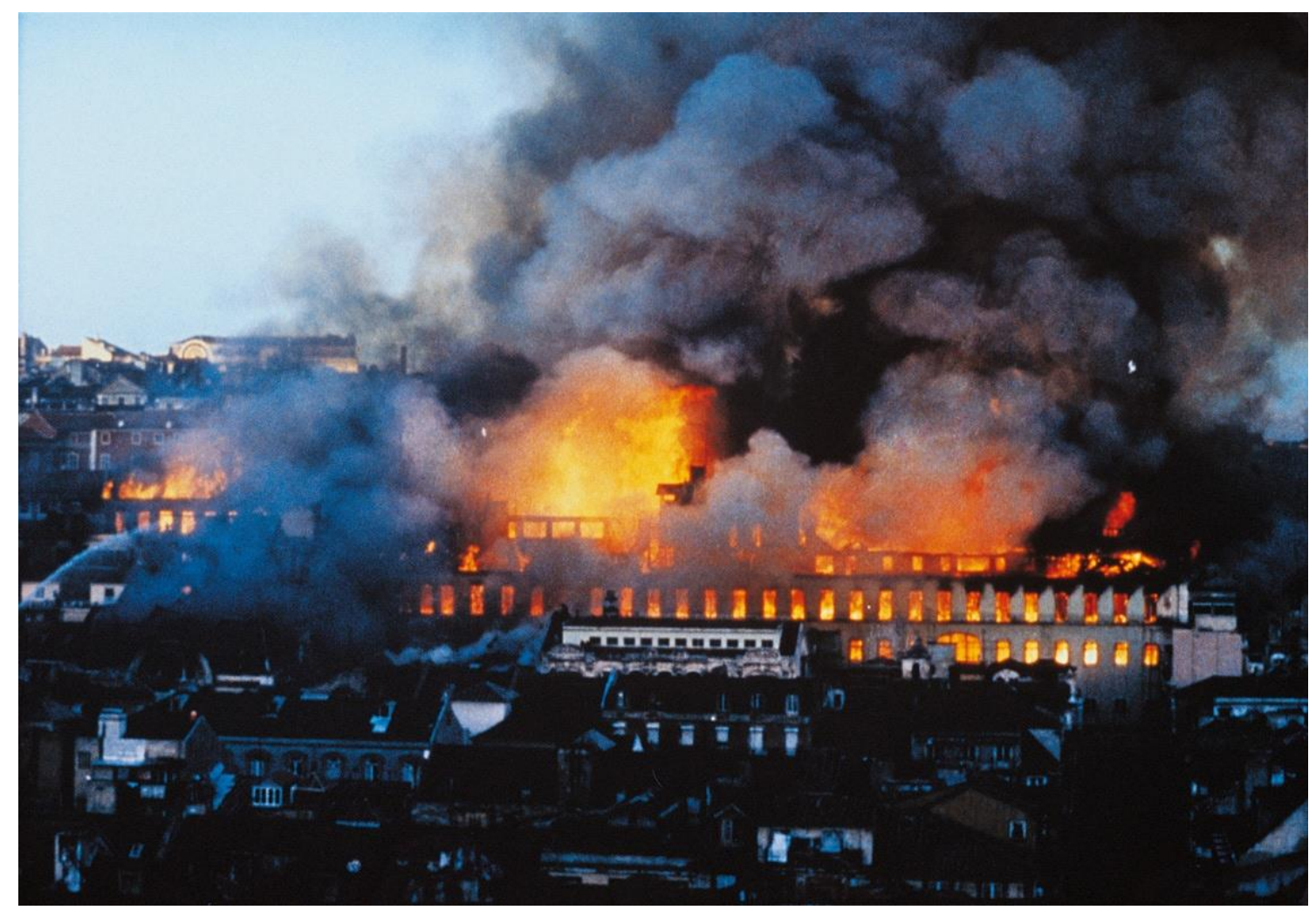

Figure 1 


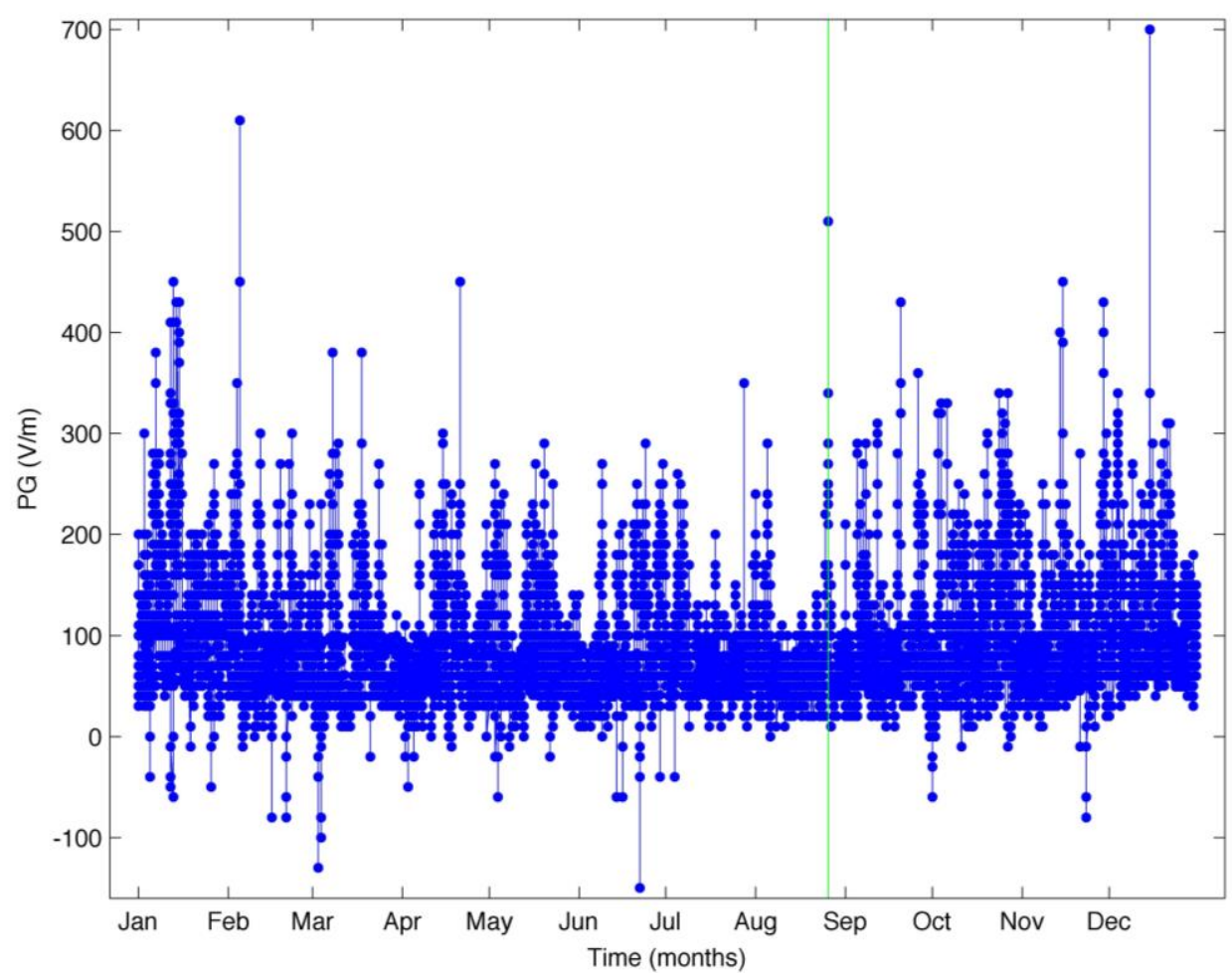

Figure 2 

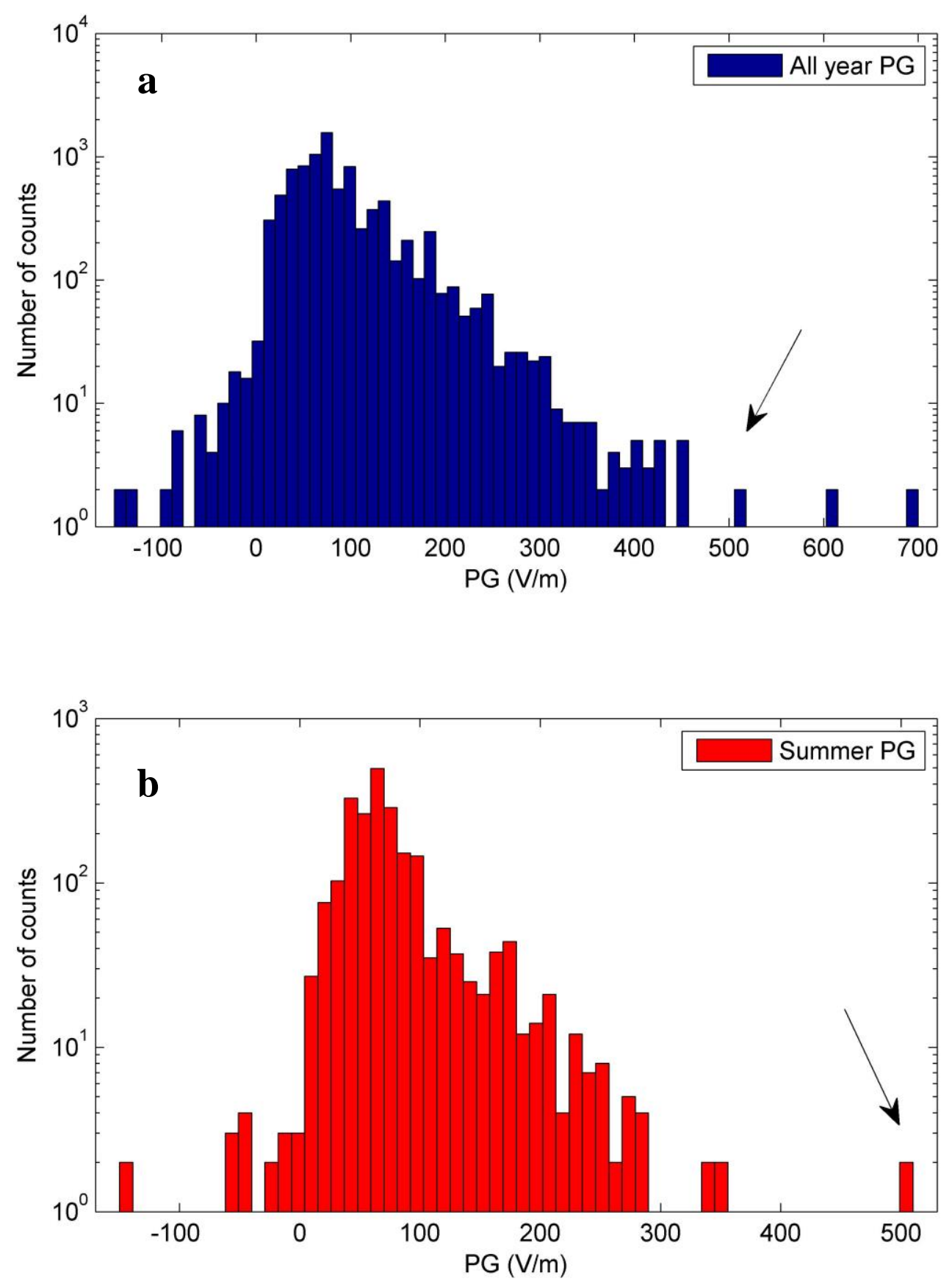

Figure 3 


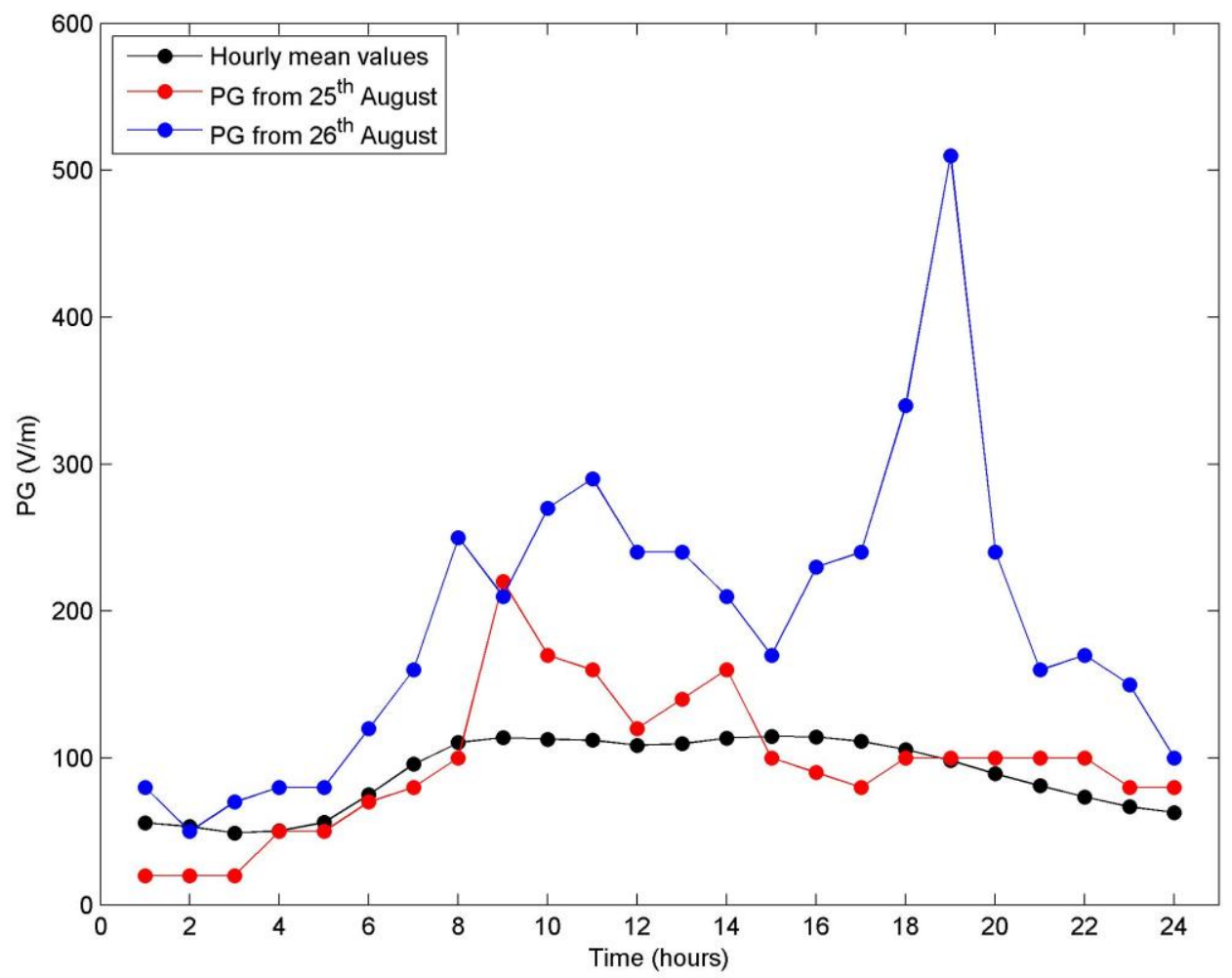

Figure 4 
a
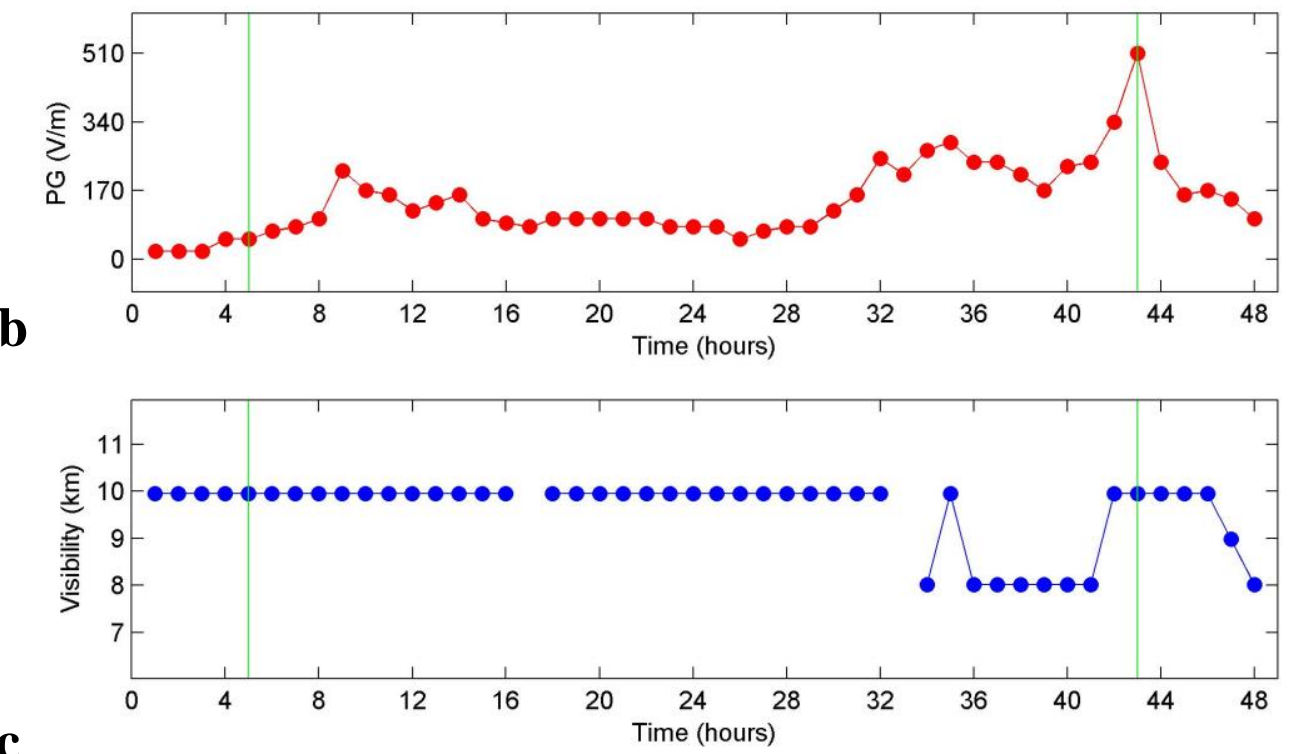

c
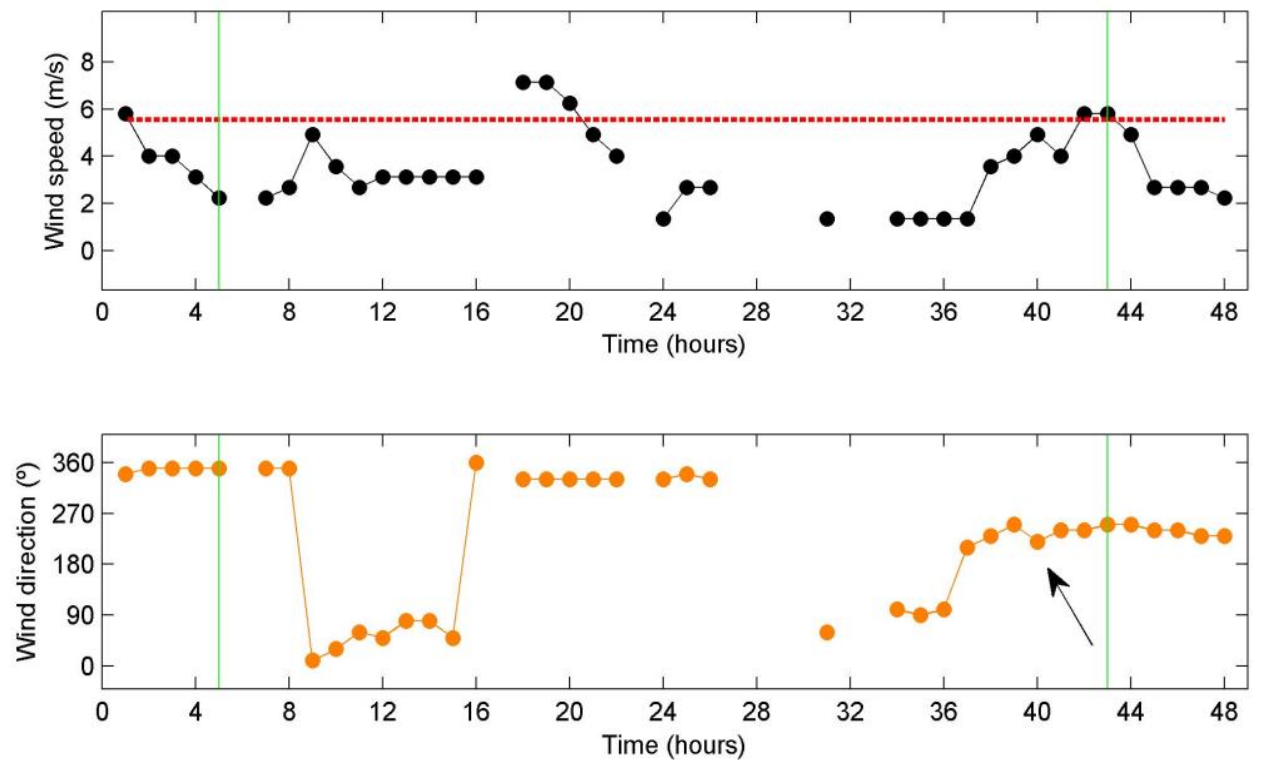

e

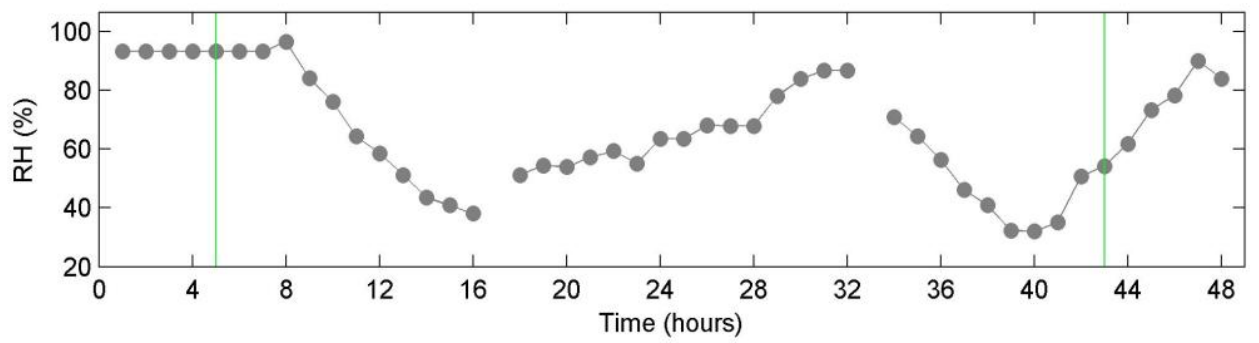

Figure 5 


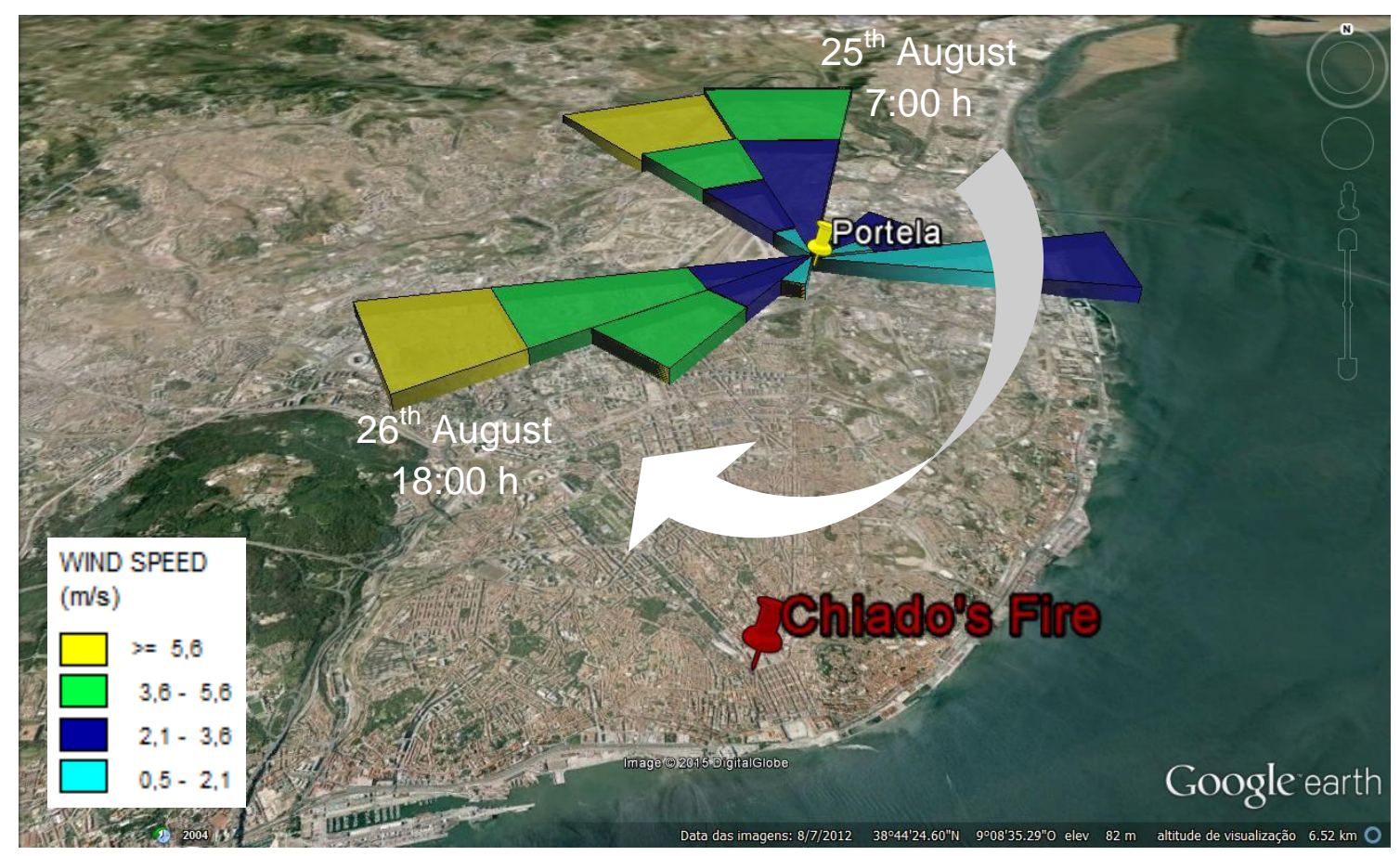

Figure 6 


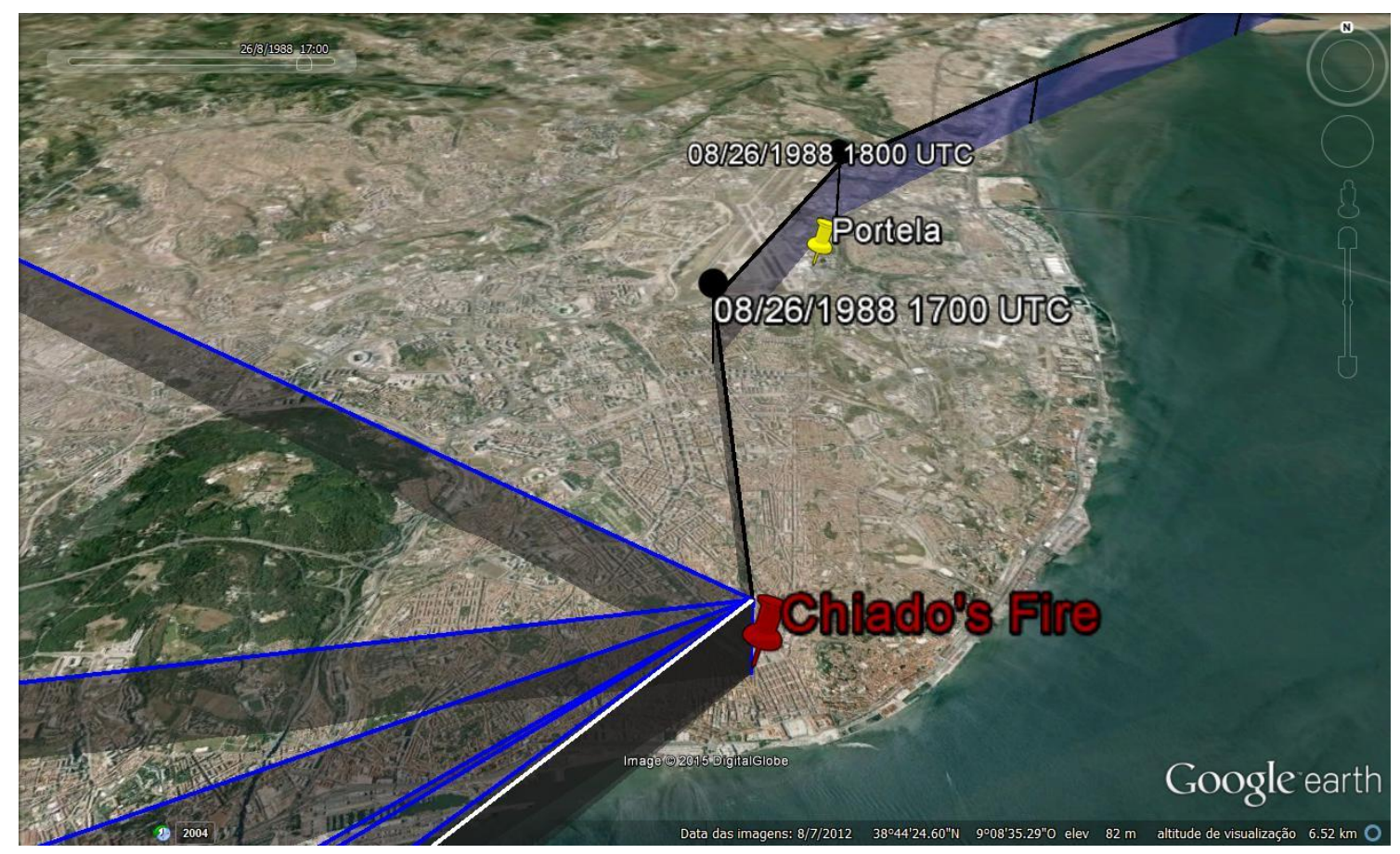

Figure 7 


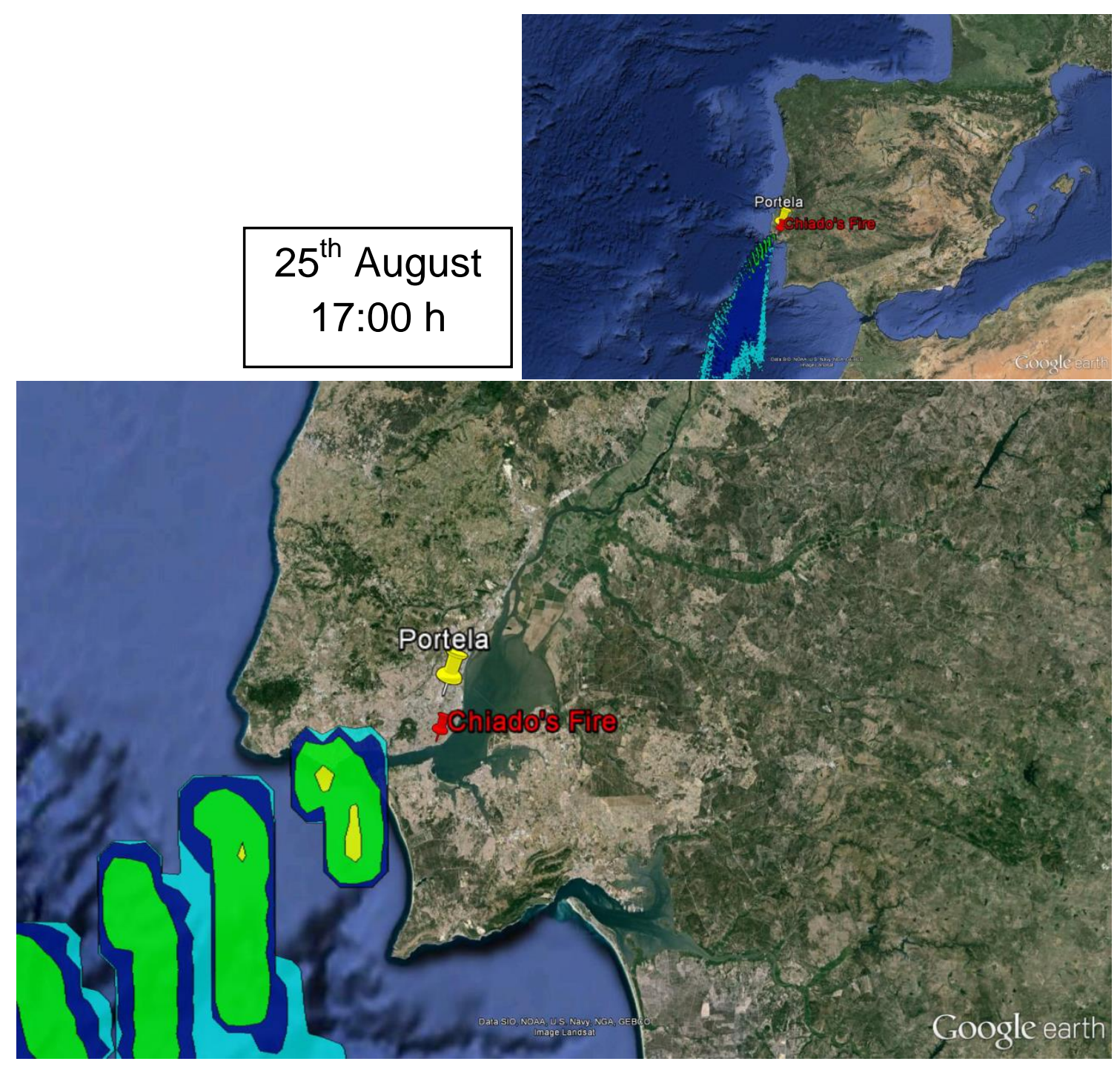

Figure 8a 


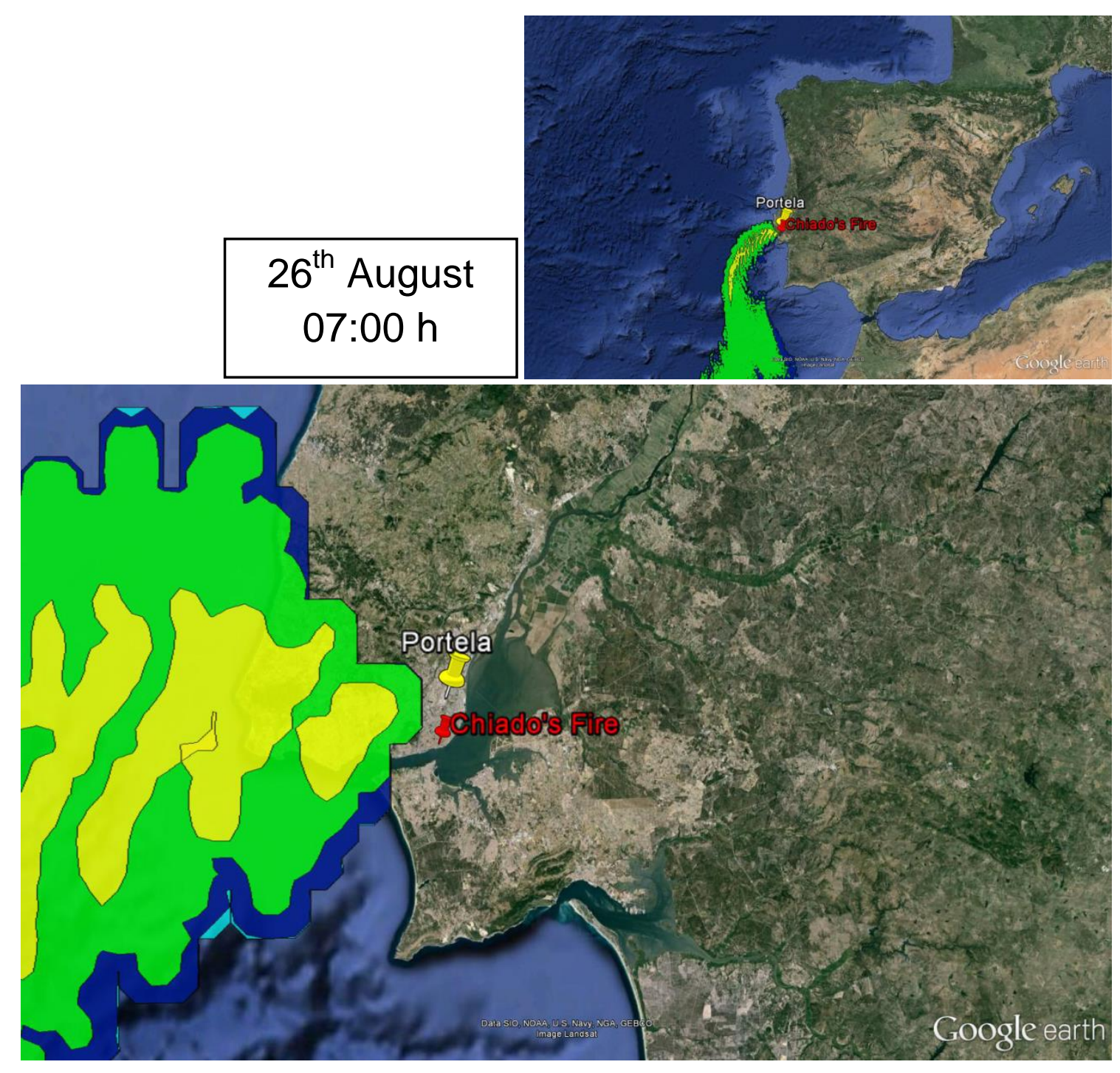

Figure 8b 


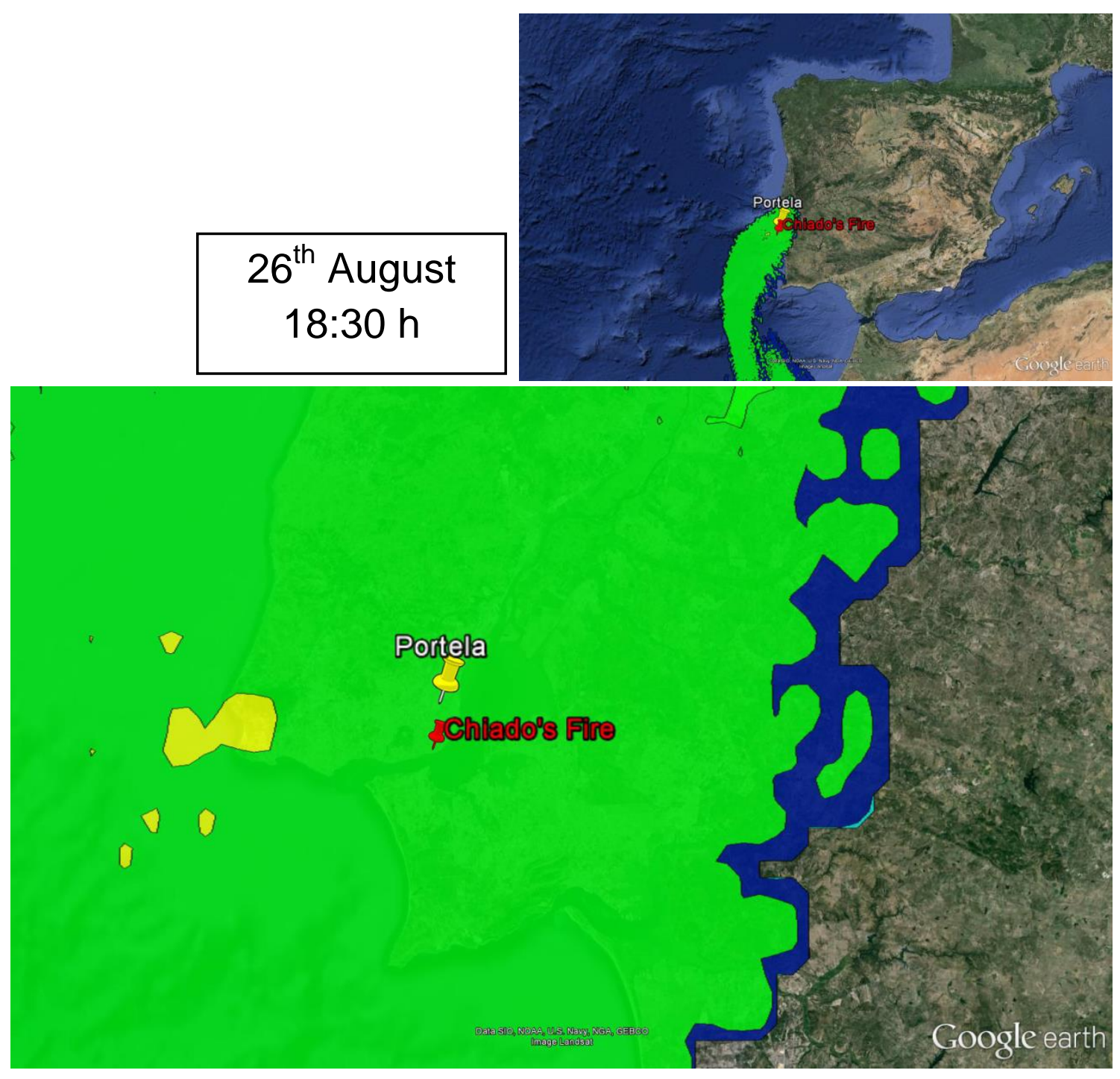

Figure 8c 